\title{
Um lance de tradução: sobre a passagem das línguas em Assia Djebar
}

\author{
Maria Angélica Deângeli*
}

[...] mais j'écrivais au moment où je recevais le coup, dans le deuil, et dans ce deuil aussi qu'est l'exil. (Assia Djebar)

\section{Cena final: um exercício de passagem}

Comecemos pelo desfecho. A cena encerra-se com um lance, um acontecimento inesperado, em francês, un coup, um golpe, um choque, mais precisamente vários golpes: un coup de fusil ("um tiro, um disparo de arma de fogo") e un coup de poignard ("uma facada"). Ou simplesmente un coup, que assim lemos ao final da história: "um pouco antes do golpe (le coup) que atingiu o coração de Atyka" (Djebar, 1997, p. 210).

Se fizermos apelo aos inúmeros sentidos evocados pelo vocábulo coup (sem contarmos as homonímias cou ["pescoço"] e cô̂t ["custo"]), notamos que ele atravessa vários domínios do conhecimento que vão do coup de foudre ("raio, faísca, lance inusitado de paixão") ao coup de balai ("varrida, vassourada"), do coup d'oeil ("olhada, olhar rápido") ao coup de théâtre ("encenação"), do coup de dés ("lance de dados") ao coup d'état ("golpe de esta-

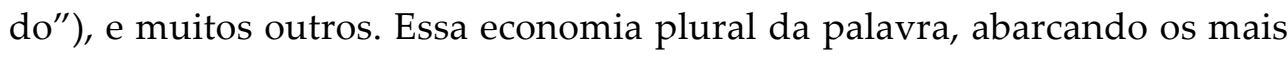
diversos lances do quotidiano, da esfera do conhecimento ou do mundo dos afetos, revela a capacidade da língua de se dizer em línguas (sempre em mais de uma língua) na singularidade dos acontecimentos.

Os exemplos podem parecer banais, mas, na letra do texto, no rastro de seus desvios, eles sinalizam para o combate (plurilíngue) que procurava levar adiante a escritora argelina Assia Djebar; e é esse movimento, por

\footnotetext{
* Universidade Estadual Paulista Júlio de Mesquita Filho - Unesp/Rio Preto.
} 
vezes conflituoso, entre as várias línguas do lugar, de tradição oral, na maioria das vezes, e a língua de escrita, supostamente estrangeira, no caso dos ex-territórios coloniais franceses, a língua francesa, que tenho nomeado frequentemente tradução em minhas leituras.

Ao colocar em cena a dualidade francês-árabe, a literatura de Djebar atesta menos o fato de um antagonismo do que uma dinâmica da diglossia por meio da qual a "verdade" de um texto se encontraria por detrás da língua, no avesso da própria língua, ou seja, no lugar da outra língua - cada língua solicitando o olhar analítico do outro - , uma espécie de contramarca, em resumo, para poder se decifrar e se refazer depois do recuo crítico. A reavaliação feita por Djebar do papel da língua francesa no campo cultural argelino representa uma mudança significativa. Ela não somente supõe uma nova relação no lugar do conflito secular entre a França e a Argélia, mas, de modo mais amplo, tal literatura se concebe como uma política de passagem pelo outro, mesmo quando a relação (cordial) entre uns e outros, no caso, entre franceses e magrebinos, parece falhar.

É, de fato, no movimento da passagem que se pode vislumbrar a tarefa da tradução; e, aqui, fazemos ecoar a já conhecida e controversa ideia de que traduzir supõe uma "operação de transporte", logo, de passagem, de uma língua para a outra.

No entanto, a partir da escrita de Djebar, interessa-nos o deslocamento operado pela e com a passagem, pois, se há passagem, essa se dá pelo desvio ou pela instância do outro. É só porque o outro está na fronteira (ou faz fronteira com) que somos convidados a permanecer do outro lado, dentro ou fora, reencenando uma espécie de shibboleth, ${ }^{1}$ tal como evoca Derrida.

Esse movimento de passagem, que em Djebar é também um ritual, significa fazer da escrita o modus operandi de um universo em desarranjo, de

\footnotetext{
${ }^{1}$ Em sua obra Schibboleth: pour Paul Celan (1986), Derrida faz uma análise detalhada da problemática referente ao vocábulo "schibboleth". De acordo com a narrativa bíblica, esse vocábulo designaria o episódio segundo o qual os descendentes da tribo de Efraim, em fuga, eram reconhecidos e presos pelos soldados de Galaad ao serem obrigados a pronunciar tal palavra, ou seja, "schibboleth", quando tentavam atravessar o rio Jordão. Assim, o vocábulo adquiriu um valor de código secreto na passagem de uma fronteira vigiada. Os efraimitas eram conhecidos por sua incapacidade de pronunciar corretamente o "schi" de "schibboleth"; eles diziam "sibbolet" e, nessa impossibilidade de reconhecerem a diferença entre "schi" e "si", acabavam expondo suas vidas. (Cf. Derrida, 1986, p. 44-45).
} 
uma sociedade na qual passar de um estado de silenciamento a um processo de significação pela voz (e pela escrita) implica, muitas vezes, silenciar a própria vida.

As marcas expressas por Djebar buscam revelar o quão inóspita pode ser a passagem (pelo outro), sobretudo quando essa se concebe como um acontecimento de língua, algo da ordem de uma passagem (quase) impossível, esse pas impossible do qual fala Derrida, para retomarmos a problemática do shibboleth, uma diferença indiferente que se faz notada exatamente pelo fato de não poder notar.

O grande lance da escrita de Djebar residiria, então, na transposição desse "falar para si", em berbere ou em árabe (falar silenciado), para o "escrever para o outro", em francês (escrever interditado); pequeno lance de tradução que torna ainda mais complexa a equação língua-políticaliteratura.

Abdelwahab Meddeb, escritor tunisiano de língua francesa, afirma que a presença da língua ausente (o árabe) na língua em que escreve (o francês) permite-lhe ordenar uma poética de escritura que não deixa de ser o esboço de uma "política sutil do poético". Entre o poético e o político, o escritor e a língua, a língua e a história, a ruptura se impõe como um exercício necessário a tais passagens, como podemos constatar em suas palavras:

O estado de uma língua depende do uso que dela fazem seus usuários. Nesse sentido ela é tributária dos áleas da história. Há mais de um século, os árabes dedicam-se ao paciente aprendizado da ruptura. Isto não se faz sem prejuízos, principalmente porque a língua árabe não inseriu em sua memória o exercício da ruptura (Meddeb, 1985, p. 137).

Como escrever, na memória da própria língua, a imposição da língua do colonizador? Como lidar com o "exercício da ruptura", quando esse se apresenta sob a forma imperiosa do colonialismo do outro? E ao escritor, o que lhe advém dessas formas bruscas de dissociações político-linguísticas e histórico-coloniais?

Ainda que, para muitos desses escritores, o francês tenha sido a única chance de dar forma ou de fazer existir uma literatura propriamente 
magrebina, o aprendizado e o exercício da escritura na "língua adversa" não se fez de maneira tranquila. Da passagem de uma língua a outra, muitas vezes, fica, para o escritor, o sentimento da perda, da ausência e até mesmo do esquecimento da perda, que se torna, então, perda absoluta.

Se o trabalho de escrita nas literaturas magrebinas está, inevitavelmente, associado à questão da língua, de forma mais precisa, ao estatuto da língua francesa na história político-literária do Magrebe, tal trabalho visa dar lugar a uma literatura que permita dizer, no lugar mesmo de sua aparição, as múltiplas vozes que se perderam, ou se esqueceram, nas tramas da história. Trabalho de recuperação e de descoberta do outro e das outras línguas cujo acolhimento caberá tão somente à literatura. Fórmula descrita de maneira exemplar por Assia Djebar:

\footnotetext{
Sim, trazer as vozes não francófonas - as guturais, as que se tornaram selvagens, as rebeldes - para um texto francês que se torna, enfim, meu. [...] Sim, fazer renascer as culturas tradicionais interditadas, maltratadas, desprezadas, há muito, inscrevê-las num texto novo, numa grafia que se torna "meu" francês (Djebar, 1999, p. 29).
}

Nessa grafia que se torna, então, propriamente sua, numa língua originariamente expropriada, é que situamos a escrita de Djebar. Escrita que prefigura a passagem no lugar da ruptura, em um lance que não seria de força (un coup de force), mas evocaria a força inerente a toda experiência de escrita, uma espécie de prova-força (épreuve [de] force) do escritor para lidar com questões tão politicamente literárias ou simplesmente linguísticas.

\section{2. $O$ conto em cena}

É somente a partir dessa empreitada político-literária que podemos ouvir as vozes com timbres variados, vozes que se cruzam e se interrompem, inúmeras vezes e em diversas línguas, em Oran, langue morte, livro do qual procurarei trazer um ligeiro esboço.

Oran, que é a cidade de AbdelKader Alloula, o poeta do teatro das línguas assassinado em 11 de março de 1993, torna-se emblema mortífero, e as vozes que aí querem se fazer ouvir são condenadas a um silêncio aniqui- 
lador. É essa destruição que o título, Oran, langue morte, faz ouvir em todos os tons.

Mireille Calle-Gruber (2001), em um estudo dedicado à obra de Djebar, afirma que Oran, langue morte só faz sentido se considerarmos a escrita em sua dimensão "apotropaica", ou seja, no contexto dessa obra, a escrita seria uma verdadeira invocação para afastar as desgraças que pairam sobre uma Argélia sitiada por desordens políticas, religiosas, econômicas e sociais, acrescidas de um fundamentalismo que passa, antes de tudo, pelo interdito lançado sobre as línguas, mais precisamente, sobre a língua francesa.

As narrativas que compõem Oran, langue morte, as quais não são escritas nem em regime ficcional, nem em regime realista, mas no entre-dois de uma mise en scène que implica distanciamento e aproximação, constituem verdadeiras cenas de exorcismo. Narrativas do derramamento de palavras, de lágrimas e de sangue, elas são um ritual lírico, uma espécie de recitação ou de prece. Convocar no lugar da linguagem, cuja regra principal é significar in absentia, as forças da violência, é uma maneira de privar a violência de presença. É torná-la refém do literário, na expectativa de fazer a língua sobreviver à sua própria catástrofe.

Um imperativo se coloca ainda, de acordo com Calle-Gruber, diante da leitura desse livro de Djebar, ou seja, no avant-coup da letra, pois aqui o tempo para compreender os acontecimentos históricos (e até mesmo literários) se impõe na iminência de sua escrita, no imediatamente antes, já que o futuro parece um tanto incerto, nesse avant la lettre somos pegos, como afirma Calle-Gruber, diante do sintagma: "Que isto possa não ter lugar" (2001, p. 136). Na singularidade de seu acontecimento, tal enunciado pressupõe que o único lugar que pode se deixar entrever é o não-lugar da literatura, com sua força poética capaz de traduzir o real numa idiomaticidade que lhe é própria. "Que isto possa não ter lugar" é a condição da escrita e a sobrevida da tradução: essa precisa ter lugar para estar no lugar, como observa Derrida, a tradução enquanto acontecimento considerável do pensamento, a lieu de tenir lieu, "tem lugar de estar no lugar" (Derrida, 2001, p. 250). 
Ao vislumbrar esse lugar de legitimidade, a literatura opera o desvio do acontecimento na língua e convoca para a cena o que está silenciado ou, muitas vezes, sentenciado à morte. Dessa forma, mantendo sua vocação de tornar palavra o acontecimento e de dar voz ao silêncio, a literatura confia sua sorte ao poder da tradução: tradução de línguas e entre-línguas, o que, na literatura de Djebar, confunde-se com o próprio ato de escrever, ou como ela o sugere:

\footnotetext{
Em resumo, escrever no Magrebe, hoje, seria: - para os franceses ditos "pieds-noirs", escrever com um ouvido e uma voz francófonas, para alguns um francês com ecos de espanhol, de italiano, de maltês etc. - para outros, os autóctones, inscrever um francês levemente desviado, já que percebido com um ouvido árabe ou berbere, escrever colado num ruído multilíngue (Djebar, 1999, p. 29).
}

É essa potencialidade das línguas, com ecos de outras línguas, que Assia Djebar coloca à prova, o que Derrida (2000), em outro contexto, designará pelo termo puissement, isto é, nem poder, nem potência, mas vacilação do subjuntivo diante do próprio acontecimento da língua: que ela aconteça (tenha lugar, chegue a algum lugar), sem dar lugar à violência que assombra todos os lugares.

Para falar desse puissement em forma de linguagem, passemos então à leitura do conto La femme en morceaux ("A mulher em pedaços"), a partir do qual Djebar elabora uma reescrita concertada, com várias vozes, em várias línguas, em mais de um sentido.

La femme en morceaux é uma das narrativas que compõem as Mil e uma noites - narrativa que conta a história da "mulher em pedaços", assassinada e esquartejada pelo marido por suspeita de adultério. No conto de Djebar, homônimo ao conto de Scherazade, a protagonista é Atyka, professora de francês em uma classe de liceu na periferia de Argel, assassinada brutalmente por fundamentalistas islâmicos que a acusam de subversão por contar histórias obscenas em língua estrangeira, o francês, aos seus jovens estudantes. Ao propor aos alunos a recriação do conto de Scherazade - atividade que se constrói como um vai e vem entre o árabe e o francês, o passado e o presente, a história e a ficção - , ao transpor tal narrativa para 
o contexto de uma Argélia mergulhada em um conflito interno entre, por um lado, o governo militar e, por outro, fundamentalistas islâmicos, Atyka encena a própria morte.

O tratamento do conto é emblemático do funcionamento do livro que se apresenta como uma escrita em fragmentos, escrita composta de sete seções e um posfácio -, em função do lugar em que aparece no conjunto arquitetural da obra, já que para Djebar a composição de uma obra é arte da construção e de engrenagens, um arranjo de passagens, de laços e de desencontros, o que se torna quase uma operação matemática. Não é, então, por acaso que La femme en morceaux está inserido no centro do livro, ao final da primeira parte que se intitula "Argélia, entre desejo e morte", antecedendo a abertura da segunda parte, intitulada "Entre França e Argélia". Percebe-se que o arranjo da construção escritural, que é, sem dúvida, arranjo arquitetural, vai ainda mais longe, pois a esse meio tempo literário responde o posfácio intitulado "O sangue não seca na língua" (Le sang ne sèche pas dans la langue). Ao falar da dor causada pela "amputação da palavra materna" numa narrativa que rememora a dor de tantas outras mulheres, silenciosas e veladas, no contexto de uma Argélia devastada por sucessivas ondas de ataques terroristas, a autora sugere uma fusão entre o serescritura e o ser-sofrimento. Se não somos só língua, pergunta-se Djebar, não seríamos, então, uma espécie de sujeito-língua-sofrimento? De maneira poética, a escritora encontra saída para aquilo que, do ponto de vista conceitual, encerrar-se-ia numa dialética cegante do gozo e da dor. "O sangue não seca na língua" remete à metáfora da própria escritura poética, para significar que, na impossível tarefa da escrita, "o sangue" (a tinta) não seca nunca, porque a língua permite à palavra dizer o impossível da dor, o impossível a ser dito e o impossível do interdito.

É este fenômeno de condução de línguas - que é a tradução com sua parte de intraduzível, tradução no sentido em que convoca para a cena a alteridade irredutível da língua - que sustenta Oran, langue morte, e, de maneira emblemática, o conto La femme en morceaux. Nessa narrativa, bilinguismo é plurilinguismo, pois, duas línguas são todas as línguas possíveis, é a inscrição de uma mutabilidade que é própria da constituição do humano. 
Não é também por acaso que o que pode aparecer como necessidade circunstancial, a imposição da língua colonial e o apagamento da(s) língua (s) materna(s), torne-se, em Oran, langue morte, bilinguismo voluntário, um amor pelas passagens, passagem pelo outro, que significa nascimento para o mundo. Muito competente em árabe, podendo ter se tornado exímia intérprete de textos islâmicos, especialista em direito muçulmano ou linguista árabe, Atyka, ao escolher o francês, escolheu mais de uma língua, como ela própria o afirma: "Eu vou ser professora de francês: e vocês vão ver, com alunos perfeitamente bilíngues, o francês vai servir para eu ir e vir em todos os espaços, assim como em todas as línguas" (1997, p. 168).

É com o puissement da língua, no sentido em que através dela (da língua) é possível dizer, ainda que de forma velada, o desejo de "tocar" o outro, que trabalha Djebar. Trabalho de invenção e de reescrita que considera a passagem entre línguas como o acontecimento da própria escritura - tal como encenado no conto La femme en morceaux.

Nesse movimento de (re)constituição e de reescritura, é interessante observar que dois corpos tipográficos, um redondo e outro itálico, alternam-se por blocos, os quais conotam, respectivamente, dois tipos de escritura, duas temporalidades diferentes. Em redondo, é narrado o conto maravilhoso: “Certa noite, em Bagdá...” (1997, p. 193). Desde o começo, pouco importa quem conta: a narrativa caminha por si só, segue seu curso. Nessa língua que segue seu próprio caminho é narrada a história da mulher cortada em pedaços, enterrada numa caixa no fundo do rio Tigre, descoberta pelo emir Haroun El Rachide e seu vizir, que é seu amigo de infância, "o justo, o belo, o bem-amado, Djaffar le Berkémenide" (1997, p. 195).

Em itálico, aparece, no decorrer de algumas páginas, um texto de uma ordem completamente diferente. Ele faz parte do gênero discursivo; a personagem principal é apresentada da seguinte forma: Atyka, professora de francês, numa classe do ensino médio em Argel, propõe a seus alunos, cerca de vinte adolescentes, meninos e meninas, a recriação de um dos contos das Mil e uma noites. De fato, mais do que um simples tratamento de gênero, o que está em jogo são os discursos dos diversos interlocutores cujo dispositivo de enunciação designa sua especificidade e suas diferenças: discurso no masculino e no feminino, na língua francesa e na língua árabe, 
de acordo com as convicções muçulmanas ou laicas, como nos faz notar a protagonista da história: "[...] tragam o texto - o texto árabe para os que quiserem e o texto traduzido" (1997, p. 180). E mais adiante: “Não estamos numa aula de ciência política nem de religião! Só para lembrar: estamos comentando alguns excertos traduzidos das Mil e uma noites" (p. 198). Ou ainda: "Continuaremos a discussão sobre as Mil e uma noites, e sobre as traduções francesas, claro; a primeira, tão expurgada, a segunda, ao contrário, exuberante!" (p. 190). Ao que os alunos replicam: "Mas, depois a senhora vai falar das diferentes traduções francesas, as que sucederam à de Galland? Parece que ele teria amenizado, isto é, censurado o original..." (p. 206).

A discussão segue em torno da tradução, das traduções francesas das Mil e uma noites, traduções por vezes censuradas, por vezes "edulcoradas", como diz a própria protagonista; a tradução aqui é o motivo, ela constitui o pano de fundo desse desejo partilhado por Atyka e seus alunos: desejo não de recuperar alguma essência original que pudesse ter sido perdida, mas de fazer valer as divergências na tentativa de desvelamento da letra estrangeira. Mas ainda é preciso perguntar: algo de fato se perdeu? O que seria a (da) experiência da perda, se não fosse a tradução? A única experiência possível da tradução é a experiência da perda? Ou, como assinala Marc Nichanian, em um ensaio intitulado Avons-nous vraiment perdu la langue à l'étranger (2001): “É preciso traduzir. É preciso traduzir no estrangeiro. É preciso traduzir numa língua perdida no estrangeiro, numa língua, de agora em diante, impotente para traduzir. É preciso traduzir a impotência para traduzir. É preciso traduzir a Catástrofe" (p. 157).

\section{Um meio tempo}

Essa terá sido desde sempre a tarefa empreendida por Assia Djebar. Sua escrita, ao traduzir para a cena literária a catástrofe de uma sociedade entregue à guerra fratricida, ocupa esse lugar em um meio tempo entre o puissement ("potenciamento") e a impuissance ("impotência").

Puissement, porque é preciso fazer com que a literatura tenha seu lugar numa sociedade devastada por quase tudo, fazer com que a letra traduza sua potência idiomática de criação, sua capacidade de resistir à inter- 
dição e sua vocação (quase metonímica) de estar no lugar, de substituir-se ao que ainda não existe, mas já está lá.

Impuissance, por outro lado, porque a língua recuperada por meio dessa literatura deve poder confessar sua falência: sua impotência para traduzir e para sobreviver, sua incapacidade de assimilar os golpes (les coups) que a sorte lhe reserva.

A partir da experiência de escrita de Djebar, podemos então dizer, de forma aporética, que escrevemos e traduzimos no puissement da impuissance, num horizonte (escritural) em que as forças contrárias são o próprio impulso do movimento. Escrevemos e traduzimos num continuum: nem no passado, nem no presente, nem no futuro; nem em árabe, nem em francês, mas, ao mesmo tempo, em árabe, em francês e em várias línguas. Estamos o tempo todo em tradução, e é pelo fato de estarmos em tradução que continuamos a falar das Mil e uma noites, tal como esse personagem do conto de Djebar, cuja vida poderia ter sido encontrada em Bagdá ou em Argel, na realidade do conto ou na ficção da realidade.

Apesar de tudo, escreve-se e traduz-se: traduz-se ao escrever e escreve-se ao traduzir, num movimento de distanciamento e de retorno, pois se não ignoramos o ensinamento já bastante sabido de acordo com o qual em nenhum momento, em nenhuma língua, estamos em nossa casa, não nos é possível esquecer de que o movimento do tornar[-se] (devenir) outro, ou tornar-se si mesmo, e do retornar (revenir), retornar para si ou para sua casa, é uma preocupação que habita, para ficarmos no domínio da morada, a experiência da tradução. Talvez, porque sempre escrevemos e traduzimos, como assinala, Assia Djebar "no momento em que recebemos o golpe (le coup), no luto e também neste luto que é o exílio" (2005, p. 95).

Em resumo, escrevemos sempre no après-coup, nesse "só depois" que já se enuncia, antes mesmo de se (d)enunciar, como um simples lance de tradução.

\section{Referências}

CALLE-GRUBER, M. Assia Djebar ou la résistance de l'écriture. Paris: Maisonneuve et Larose, 2001.

DJEBAR, A. Oran, langue morte. Paris: Actes Sud, 1997. 
Dialogue: Assia Djebar, Andrée Chédid, Mireille Calle-Gruber. In: CALLE-GRUBER, M. (Org.). Assia Djebar, nomade entre les murs... Paris: Maisonneuve et Larose, 2005. p. 93-104.

DERRIDA, J. Schibboleth: pour Paul Celan. Paris: Galilée, 1986. H.C. pour la vie, c'est-à-dire... In:CALLE-GRUBER, M. Hélène Cixous: croisées d'une oeuvre. Colloque de Cerisy. Paris: Galilée, 2000. p. $13-140$.

. Le toucher: Jean-Luc Nancy. Paris: Galilée, 2001.

MEDDEB, A. Le palimpseste du bilingue: Ibn' Arabi et Dante. In: KHATBI, A. et al. (Org.). Du bilinguisme. Paris: Denoël, 1985. p. 125-140.

NICHANIAN, M. Avons-nous vraiment perdu la langue à l'étranger. In: TTR: traduction, terminologie, rédaction. vol. 14, n. 2, 2001. p. 141-166. Disponível em: http:/ / www.erudit.org/revue/ttr/2001/v14/n2/000573ar.pdf . Acesso em: 30 set. 2015.

Resumo: Este texto discute a problemática da escrita de língua francesa na literatura magrebina contemporânea, mais precisamente na obra da escritora argelina Assia Djebar. A reavaliação feita por Djebar do papel da língua francesa no campo cultural argelino representa uma mudança significativa. Tal literatura não somente supõe uma nova relação no lugar do conflito secular entre a França e a Argélia, mas se concebe como uma política de passagem pelo outro. Dessa forma, este trabalho também busca interrogar em que sentido a escrita na língua do outro constitui uma tarefa de tradução.

Résumé: Ce texte discute la problématique de l'écriture d'expression française dans la littérature maghrébine contemporaine, plus précisément à partir de l'oeuvre de l'écrivain algérienne Assia Djebar. La réévaluation faite par Djebar du rôle de la langue française dans le champ culturel algérien représente un changement significatif. Un tel changement suppose non seulement un nouveau rapport à la place du conflit séculaire entre la France et l'Algérie, mais il atteste aussi le fait qu'une telle littérature se conçoit en tant qu'une politique de passage par l'autre. De cette façon, ce 
travail interroge dans quel sens l'écriture dans la langue de la langue de l'autre évoque une tâche de traduction. 